Policy Research Working Paper 4360

\title{
Foreign Direct Investment in Latin America during the Emergence of China and India:
}

\author{
Stylized Facts \\ Javier Cravino \\ Daniel Lederman \\ Marcelo Olarreaga
}

The World Bank

Latin America and the Caribbean Region

Office of the Chief Economist

September 2007 
Policy Research Working Paper 4360

\section{Abstract}

In spite of the growing concerns about foreign direct investment being diverted from Latin America to China and India, the best available data show that Latin America has performed relatively well since 1997. Foreign capital stocks from OECD countries-and the United States in particular-in China and India are still far from those in the largest Latin American economies. The evidence shows that foreign capital stocks in China increased more than in Latin America during 1990-1997, but not as much since 1997. In fact, Latin America has actually performed better than China since 1997 given its lack of relative growth. The growth of foreign capital stocks in India was more stable than in China. Nonetheless, after controlling for shocks emanating from the source countries and bilateral distance between source and host countries, this paper finds a significant change in foreign capital stocks relative to China between 1990 and 1997, but no change relative to India.

This paper-a product of the Office of the Chief Economist for Latin America and the Caribbean-is part of a larger effort in the department to understand the effects of the growth of China and India on Latin American and Caribbean economies. Policy Research Working Papers are also posted on the Web at http://econ.worldbank.org. The author may be contacted at dlederman@worldbank.org.

The Policy Research Working Paper Series disseminates the findings of work in progress to encourage the exchange of ideas about development issues. An objective of the series is to get the findings out quickly, even if the presentations are less than fully polished. The papers carry the names of the authors and should be cited accordingly. The findings, interpretations, and conclusions expressed in this paper are entirely those of the authors. They do not necessarily represent the views of the International Bank for Reconstruction and Development/World Bank and its affiliated organizations, or those of the Executive Directors of the World Bank or the governments they represent. 


\title{
Foreign Direct Investment in Latin America during the Emergence of China and India: Stylized Facts
}

\author{
Javier Cravino, Daniel Lederman and Marcelo Olarreaga ${ }^{*}$
}

The findings, interpretations and conclusions expressed in this paper are entirely those of the authors. They do not necessarily represent the view of the World Bank, its Executive Directors, or the countries they represent.

\footnotetext{
* We are grateful to Pravin Krishna for helpful discussions and comments. Financial support from the World Bank's Latin American and Caribbean Regional Studies Program is gratefully acknowledged.
} 


\section{Introduction}

Foreign direct investment (FDI) has been increasing at an extraordinary speed during the past 20 years. In the second half of the last decade, world inflows grew at an annual rate of almost 40 percent, reaching $\$ 648$ billion in $2004 .{ }^{1}$ Foreign capital stocks (FCS) were multiplied by a factor of 5 between 1990 and 2004, rising from \$1,770 billion in 1990 to almost $\$ 9$ trillion in $2004 .^{2}$ An even larger increase was reported in developing countries, where stocks went from $\$ 364$ billion to over $\$ 2,230$ billion over the same period.

In particular, foreign direct investment inflows to Latin America and the Caribbean (LAC) continuously grew during the 1990s, up to almost half of total inflows into developing economies in 1999. In that year, FDI accounted for 25 percent of Latin America's gross fixed capital formation. ${ }^{3}$ Although there was a slowdown in these inflows at the beginning of the $21^{\text {st }}$ century, by 2004 aggregate stocks in Latin America reached $\$ 600$ billion dollars, about six times more than in $1990 .^{4}$

There is a growing concern that the growth in China and India may present a challenge to other developing countries. The low wages and the large populations of these countries may entice multinational enterprises to relocate their production facilities there. In fact, FCS in China grew at an amazing speed, from \$20 billion in 1990 to \$245 billion in 2004, the largest FCS in the developing world. At the same time, stocks in India increased from $\$ 1.6$ to almost $\$ 40$ billion over the same period.

\footnotetext{
${ }^{1}$ UNCTAD 2005

${ }^{2}$ Throughout the paper we refer to stocks of foreign direct investment (FDI) as foreign capital stocks (FCS).

${ }^{3}$ UNCTAD 2004 and UNCTAD 2005

${ }^{4}$ These figures were taken from UNCTAD foreign direct investment database. We do not include

Bermuda, Cayman Islands and Virgin Islands in the Latin American figures as part of LAC.
} 
This paper examines the evolution of foreign capital in Latin American economies by comparing them to China and India. In particular, we study total inward stocks into each country, inward stocks from major OECD countries, inward stocks from the U.S. and inward stocks from the U.S. in the manufacturing sector.

Although China appears as the developing economy with the largest FCS, its stocks from OECD sources and the U.S. in particular are smaller than those of the major Latin American countries. In fact; FCS in China are still smaller than in Latin America if we control for county size. However, Hong Kong (China) and Mainland China together accumulated larger stocks from OECD investments than any Latin American country. FCS in India, on the other hand, are still small compared to those in the major Latin American countries.

We then analyze the evolution of the relative stocks by looking at how they changed between 1990,1997, and 2003, because the data suggest that time trends of Chinese FCS changed after 1997. We find that China accumulated larger stocks than Latin America since 1990, but not since 1997. This was not the case for U.S. capital in the manufacturing sectors of host countries, where stocks in China grew faster than in most Latin American countries between 1997 and 2003. This growth, however, is far from impressive, and it is mainly explained by faster GDP growth. In contrast, Indian FCS grew faster than in Latin American countries during the whole period 1990-2003, but this growth was slower than in China during the entire period according to both the U.S. and the OECD data.

Finally, we analyze the evolution of OECD FCS in Latin America relative to those in China and India after controlling for shocks affecting the source countries as well 
as geographic distance between source and host countries. This evidence suggests that OECD capital stocks in Latin American economies relative to China changed between 1990 and 1997, but not between 1997 and 2003. At the same time, we did not find any statistically significant change in the stocks relative to China plus Hong Kong (China) and India during this period, thus implying that China plus Hong Kong (China) and India receive FDI from different sources than Latin American economies. Nevertheless, these stylized facts do not tell us much about whether FDI flows to China, Hong Kong (China) plus China, or India since 1990 have come at the expense of FDI to Latin American countries. Further econometric analysis is required to address this question (see, for example, Eichengreen and Tong 2005; Cravino, Lederman, and Olarreaga 2006; Garcia Herrero and Santabárbara 2005; and Chantassasawat et al. 2004).

The rest of this paper is organized as follows. Section 2 describes the data. Section 3 compares FCS levels in Latin America, China, China plus Hong Kong (China), and India. Sections 4 and 5 analyze the evolution of these stocks. Section 6 studies the conditional relative stocks, and section 7 provides concluding remarks.

\section{Data Description}

The analyses in this paper use data on aggregate inward FCS, outward stocks from some OECD countries, outwards stocks from the U.S., and outward stocks from the U.S. in the manufacturing sectors of China, China plus Hong Kong (China), India, and Latin American countries. Data on aggregate stocks was collected from UNCTAD, which are available from its website. ${ }^{5}$ UNCTAD reports aggregate FCS at book values or at historical cost in millions of U.S. dollars. The aggregate inward data is attractive since it

\footnotetext{
${ }^{5}$ www.unctad.org
} 
draws a general picture of the relative evolution of FCS. One drawback of this dataset is that the agencies that collected the original data vary from one host country to another. This makes comparisons between different host countries difficult to interpret. Moreover, these aggregate data do not provide information on FCS by source-host country pairs. Since the major sources of FCS for China are different from those of Latin American countries, it is prudent to focus on some attention on source countries that are important for Latin America ${ }^{6}$.

To address these issues, we also use data on bilateral outward stocks from major OECD countries. These data were taken from OECD statistics and UNCTAD for the period 1990-2003. ${ }^{7}$ The OECD reports the bilateral FCS of 29 OECD countries into 235 host economies in millions of U.S. dollars from 1982 to 2003. One shortcoming of this dataset is that observations for most Latin American countries are missing for some source countries. We therefore expanded this dataset using data from UNCTAD for 29 source countries into 190 host countries. For those countries for which the UNCTAD data is reported in national currency, we transformed the figures into U.S. dollars using the end of period exchange rate, which was taken from the OECD. We then use the OECD dataset unless the observations are missing. ${ }^{8}$ Even after including the observations from UNCTAD, we continue to have several missing observations for some country pairs. For this reason, in sections 3, 4 and 5 we restrict the analysis to major source countries that have most of the observations for the Latin American countries. The selected source countries were Canada, Germany, France, Japan, Netherlands, Spain, Switzerland, the United

\footnotetext{
${ }^{6}$ IADB [2004]

${ }^{7}$ The OECD data is available from www.sourceoecd.org.

${ }^{8}$ Data for Australia for the period 1990-2000 was also taken from the UNCTAD, since OECD reports data for the fiscal year.
} 
Kingdom, and the United States. ${ }^{9}$ Together they accounted for more than 68 percent of total FCS in the major Latin American countries as of 2002. ${ }^{10}$ The complete dataset was used in the regression analysis of section 6 , where the data were also deflated by the U.S. Producer Price Index (PPI). ${ }^{11}$ Although the agencies that collected the OECD and UNCTAD databases vary from one source country to another, they remain the same within the host countries, which facilitates international comparisons, especially in econometric analyses that control for source-country effects as in section 6 below.

Data for total outward stocks from the U.S. were taken from the Bureau of Economic Analysis. ${ }^{12}$ These stocks are reported on a historical cost basis in millions of U.S. dollars. These data are of particular interest for our purpose due to the visible presence of U.S. multinational corporations in Latin American countries as well as in China, Hong Kong (China), and India. An advantage of these data is that it was collected by the same agency. Finally, we take the U.S. stocks in the manufacturing sectors of the host countries from the same source. Again, these data are of special interest since companies in this sector seem to be potentially more inclined to relocate production to China or India as they search for reductions in labor costs.

To make the analysis more tractable and due to data availability on bilateral stocks from the OECD, we focus on nine Latin American countries. We include the major countries (Argentina, Brazil, Chile, Colombia, Mexico and Venezuela) as well as some Central American countries that may be of particular interest (Costa Rica,

\footnotetext{
${ }^{9}$ Stocks from Spain were calculated by accumulating the flows, which were taken from the OECD. Japan does not report stocks in 1995 for any Country. It does not report stocks in any year for Colombia, Costa Rica, Guatemala, Venezuela and in Argentina and Chile since 1996.

${ }^{10}$ UNCTAD 2004. This figure does not include stocks into Mexico. However, FDI flows from these countries comprised more than 90 percent of Mexican FDI inflows in 2002.

${ }^{11}$ The PPI was taken from the International Monetary Fund's International Financial Statistics database.

12 www.bea.org
} 
Guatemala and El Salvador) due to their dependence of manufacturing exports that compete with Chinese exports in the U.S. market. Together, these countries accounted for 86 percent of Latin Americas FCS in 2003.

\section{Relative stocks in $\mathbf{2 0 0 3}$}

In this section we analyze the FCS levels in Latin American countries relative to those in China, China and Hong Kong (China) together, and India. Table 1 reports these ratios for the world total, OECD, U.S. and U.S. manufacturing FCS.

The first column shows how important China has become as a destination for FDI: by 2003 total FCS in China were bigger than in any Latin American country. Brazil and Mexico, the countries with the largest FCS of the region, had only 58 and 73 percent of China's stock respectively. At the same time, Argentina, Chile, and Venezuela reported less than a quarter of China's FCS.

Nonetheless, OECD FCS in China were significantly smaller than in the major Latin American countries. In particular, Mexico had almost twice as much capital from the OECD than China. This disparity is more noticeable in disaggregated data from the U.S. The third column of table 1 shows that the relative stocks from the U.S. were bigger than both the aggregate and the OECD relative stocks. This reflects the fact that the U.S. is a relatively more important source of FDI for Latin American countries than for China. In 2003 , U.S. stocks in China were only $\$ 11.5$ billion, quite small compared to the $\$ 59$ billion in Mexico or the $\$ 37$ billion in Brazil. These data show that when it comes to OECD and U.S. stocks, China is still far from being a major host of FCS. 
The last column in the first panel of table 1 reports the relative stocks from the U.S. in the manufacturing sector. Again China does not appear as a major host of FCS, with one third of the capital accumulated in Mexico. However, in this sector Chinese stocks are larger than those of Argentina, Chile, and Venezuela, suggesting that China has been relatively more attractive to capital in the manufacturing sector.

China and Hong Kong (China) jointly had accumulated FCS for almost $\$ 188$ billion, more from the OECD than any Latin American country by 2003. China and Hong Kong (China) are important hosts of U.S. FCS, being considerably bigger than every country from Latin America with the exception of Mexico.

India, on the other hand, is a long way from reaching the FCS levels of the major Latin American countries countries. By 2003, total FCS in Mexico alone were more than 5 times bigger than in India. The OECD data shows that this gap is bigger for the largest countries, but it is smaller for Costa Rica, El Salvador and Guatemala.

The last two columns of the table reveal that India is not a major destination for U.S. capital. Except for Argentina and Chile the difference between Latin American and Indian stocks is larger in the manufacturing sector.

Differences in FCS in Latin American countries and China and India may only reflect differences in country sizes. Thus, we proceed to normalize the FCS by each country GDP and recalculate the relative stocks. The U.S. FCS in the manufacturing sector were normalized with the manufacturing value added in each country ${ }^{13}$. The resulting ratios are reported in Table 2. After controlling for country size, China appears with less FCS than any Latin American country. This is true for the different indicators of

\footnotetext{
${ }^{13}$ GDP and Value Added in manufacturing in current U.S. Dollars were taken from WDI. Manufacturing Value Added for China in Yuans was taken from China Statistical Yearbook, and transformed into dollars using the period average exchange rate from IFS.
} 
FCS. Latin American countries also have more FCS from the OECD and the U.S. relative to their size than China and Hong Kong (China) put together. The last panel shows that FCS in India are even more irrelevant once we control for country size.

In brief, the general view of China and India as major destinations for foreign capital can be deceptive. When looking at stocks, we observe that India is still far from the major Latin American economies. China on the other hand, has a larger level of capital stocks than these economies, although this is not the case when we restrict the source countries to the OECD or the U.S. In fact, Latin American countries have large FCS than China and India relative to their size. Finally, it is important to notice that stocks in China are particularly large in the manufacturing sector, whereas stocks in India are relatively smaller in the manufacturing sector. However, the snapshot of the relative FCS position in 2003 hides important over-time trends, as discussed in the following section.

\section{Evolution of the FCS between 1990 and 2003}

This section analyzes the evolution of FCS in Latin America relative to those in China, China and Hong Kong (China), and India. More specifically, we calculated these relative stocks as:

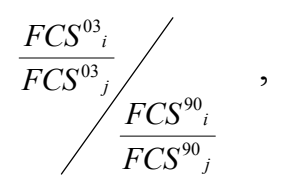

where i stands for the Latin American countries, and j stands for China, China plus Hong Kong (China), or India. When this ratio is less than one, the relative position of host 
country $i$ with respect to country $j$ was lower in 2003 than in 1990 . The corresponding calculations are reported in Table 3.

The first column of the table reports that aggregate stocks in China have grown significantly faster than in Latin America during this period. Between 1990 and 2003 stocks in China grew two times faster than in Argentina, Chile and Colombia, three times faster than in Brazil and Costa Rica and four times faster than in Guatemala. OECD stocks in China also grew faster than in Latin American countries.

Column 3 shows that the fall in the relative stocks is more dramatic in the U.S. data. For most countries, relative stocks in 2003 were less than 20 percent of its 1990 level. In Brazil, Colombia, and Costa Rica the ratios are below 0.1. This reveals that U.S. stocks in China caught up with those in Latin American countries. The relative decline was particularly remarkable in the manufacturing sector. Relative stocks in this sector in the major countries declined the most: stocks in Brazil, Mexico, Argentina, and Colombia were at 5 percent or less than its 1990 levels. Again, this reflects that China is relative more attractive to capital in the manufacturing sector.

The second panel in the table displays the changes in the stocks relative to those in China and Hong Kong (China). Column 5 shows that aggregate relative stocks in China and Hong Kong (China) grew faster than in most Latin American countries. However, this pattern is reversed when we focus on the stocks from OECD. Most countries from Latin America accumulated more stocks from the OECD than China and Hong Kong (China) during this period. In fact, only in Brazil and Guatemala the relative stocks from the OECD turn out to be smaller in 2003 than in 1990. 
Column 7 shows results for the U.S. data. Again we find that stocks in China and Hong Kong (China) grew faster than in most Latin American countries. In the manufacturing sector, the ratios are significantly smaller than in China, suggesting that most of the growth in the manufacturing stocks in China and Hong Kong (China) was due to FDI in mainland china gather than Hong Kong (China).

Finally, the last panel of Table 3 reports the results relative to India. Not one of the Latin American countries accumulated more stocks than India during the period. Indeed, Latin American total stocks relative to India fell even more than those relative to China. Unlike those of China, however, these ratios are significantly bigger when we repeat the exercise with the stocks from the OECD.

U.S. stocks in India also grew faster than in Latin American countries. Contrary to what happened with China, it is interesting that this growth was less pronounced in the manufacturing sector. The most remarkable example is that of Chile, where total stocks relative to India in 2003 were about one third of those in 1990 but were 37 percent bigger in the manufacturing sector.

It is interesting to estimate the share of these variations explained by GDP growth. We do this by normalizing the FCS by the GDP and value added in manufacturing before calculating the ratios of the relative stocks between 2003 and 1990. The results are reported in Table 4. The first panel of the table shows the results for China. FCS in China grew more than in Latin America even after controlling for GDP growth. Although the ratios are still less than one, they are significantly higher than those in Table 3, reflecting that GDP growth was faster in China than in Latin American countries. FCS in India also grew more than in Latin America, even after normalizing by the GDP growth. 
In summary, we find that Latin American stocks were smaller relatively to those of China and India in 2003 than in 1990, even after controlling for GDP growth. This is less true when we consider China and Hong Kong (China) as one economy. Nevertheless, there are significant differences among source and host countries: whereas in China stocks from the U.S. and the OECD grew relatively faster, aggregate stocks grew faster in India. Another interesting aspect when comparing the growth of the stocks in China and India is that U.S. stocks in China grew more in the manufacturing sector, whereas U.S. stocks in India grew more in the aggregate.

\section{Evolution of relative FCS between 1997 and 2003}

To get a clearer picture of the evolution of the relative stocks over time we repeat the exercise using 1997 as a benchmark year. Table 5 reports the ratios of the relative stocks in 2003 divided by those in 1997.

The results are quite surprising. Column 1 shows that aggregate stocks in most Latin American countries grew faster than in China: only Argentina and Colombia accumulated fewer stocks during this period. What is perhaps more unexpected is that the major winners are Central American countries: between 1997 and 2003, FDI stocks grew 4 times faster in El Salvador than in China, and about two times faster in Mexico and Costa Rica. Stocks in Brazil, Chile, Guatemala and Venezuela also increased more than in China during this period.

Chinese stocks from the OECD did not grow faster than those in Latin American countries. The second column shows that in general stocks in China and Latin America 
grew at similar rates since 1997. Argentina, El Salvador and Mexico actually accumulated more stocks than China since this year.

We then turn to the stocks from the U.S. In this case, stocks in China increased more rapidly than those in Latin America. This however was not the case for Mexico and El Salvador, which once again grew faster than China. This seems to be at odds with the perception that foreign investment in Mexico and Central America are receding because firms are increasingly moving their production facilities to China.

Column 4 reports the ratios in the manufacturing sector. Here, we do find that stocks in China continued to outgrow those in Latin America for the period 1997-2003. In particular it is worth highlighting that stocks in the manufacturing sector in Mexico relative to China were only 60 percent of its 1997 level. At the same time, relative stocks in Argentina and Brazil were less than one fourth of their 1997 levels. It is however important to acknowledge that even in the manufacturing sector, the growth of Chinese FCS was not spectacular: during the same period, stocks grew faster in Chile, and at about the same rate in Costa Rica.

The second panel exhibits the evolution of FCS relative to China plus Hong Kong (China). The ratios for the total FCS are very similar to those in China, thus indicating that FCS in Hong Kong (China) and in the mainland grew at similar rates during the period. Again, the aggregate FCS in most Latin American countries grew faster than in China plus Hong Kong (China) since 1997. The results using the major OECD countries and the U.S. as the only sources of FCS are also quite similar to those in China. Differences appear in manufacturing-sector FCS. In this case, we find that the growth in 
FCS in China plus Hong Kong (China) was smaller than in Chile, Costa Rica, and Venezuela.

Regarding FCS in India, the first column on the last panel shows that for the aggregate they grew less than in Mexico, Costa Rica, and El Salvador. However, total stocks in India did grow faster than in the other Latin American countries, especially than in Argentina, Chile, and Colombia. This was also the case for the OECD stocks. Here stocks in India increased more rapidly than in every country in our sample with the exception of Mexico and El Salvador.

Even more than the OECD stocks, U.S. stocks in India continued to grow faster than those in Latin American between 1997 and 2003. In this period, India accumulated about three times more FCS from the U.S. than Argentina, Brazil, Chile, or Guatemala, and about 5 times more than Colombia or Costa Rica. Even Mexican relative FCS were only 0.79 of the 1997 level. Only stocks in El Salvador grew at the same rate as those in India. Finally, when we concentrate on the manufacturing sector we find that the stocks in India have increased more than in Latin American countries during this period.

Table 6 repeats the exercise after normalizing the FCS. Again, we find that part of the relative growth in China FCS can be attributed to faster GDP growth. The ratios here are much lower than those in Table 5. Total and OECD FCS in Latin American countries grew more than in China relative to their GDP. U.S. FCS in the manufacturing sector grew more in China than in Latin America during this period, although this growth is was less than in Chile, Costa Rica and Venezuela. On the other hand, FCS in India grew faster than in Latin America during this period. 
In short, aggregate and OECD FCS in China did not outgrow those in Latin America between 1997 and 2003. Even for the U.S. stocks, we find that some countries like Mexico and El Salvador accumulated more FCS than China since 1997. Only in the manufacturing sectors China accumulated more capital than most Latin American countries, although these FCS data were significantly smaller than those reported for the entire period. Latin American countries have in general performed better than China relative to their lack of relative growth. India, in contrast, continued to accumulate FCS faster than our sample of Latin American economies between 1997 and 2003.

\section{Conditional relative stocks}

As noted above, relative FCS trends differ across source countries, thus suggesting that bilateral characteristics may be important in determining the allocation of FDI. Consequently, this section analyzes trends in FCS while controlling for distance and source-country characteristics. To deal with these issues, we use the OECD and UNCTAD data to estimate cross sectional regressions for each year with source and host country dummies and the bilateral distance between source and host countries ${ }^{14}$. In each regression we exclude the dummy for China as a host country, and then interpret the dummy-variable coefficients of the other host countries as the effect of each host country relative to China. We then repeat the exercise excluding the dummies for China plus Hong Kong (China) and India. This econometric approach is consistent with existing literature on the determinants of FDI in developed and developing countries, which

\footnotetext{
${ }^{14}$ Since we are controlling for source country fixed effects, we include all source and host countries that are available in the dataset, but exclude small host countries with populations below 500,000 people. The bilateral distance is measured in miles and was taken from Rose (2004).
} 
suggests that host and source country characteristics, as well as their bilateral characteristics affect the investment decisions of investor firms (see, for example, Carr et al. 2001, and Blonigen et al. 2003).

Table 7 reports the coefficients and the confidence intervals of the dummies for the regressions in the years 1990, 1997, and 2003. The first panel shows the results when we exclude the dummy for China. After controlling for source-country fixed effects and distance, Mexico no longer appears as the major destination for OECD stocks. Instead, Brazil comes out as the major recipient in Latin America. After conditioning on distance and source countries fixed effects, we find the dummies in 1997 decreased relative to those in 1990. However, the relative-FCS coefficients from 1997 and 2003 are not significantly different. This finding confirms that China has not become relatively more attractive for OECD capital than Latin American countries since 1997. In contrast, the relative-FCS coefficients with respect to China plus Hong Kong (China) and India, do not vary significantly over time. All the coefficients for 2003 are within the confidence intervals of the 1990 coefficients.

\section{Concluding remarks}

In sum, India is still far from the aggregate levels of FCS found in the major Latin American economies, while China and Hong Kong (China) as a whole have had higher FCS since 1990. Regarding China, when we restrict the source countries to the OECD or the U.S. we find that FCS in China have grown significantly faster than in Latin America between 1990 and 2003, especially those originating in the U.S. and destined to the manufacturing sectors of host countries. Nevertheless, this relative growth has been less 
evident since 1997. From this year on, we find that China accumulated more FCS than Latin American countries only in the manufacturing sector. Even here, U.S. stocks in China did not grow faster than in Chile or Costa Rica. At the same time, stocks in India increased more than in Latin America in both periods. This was true both for stocks originating in the OECD and in the U.S., but their growth were less significant than that of China between 1990 and 1997.

After controlling for shocks emanating from source countries and bilateral distance between source and host countries, the OECD data suggest that the significant change in Latin America's FCS relative to China occurred between 1990 and 1997. However, even this econometric analysis is silent with respect to any substitution effects that might have affected Latin America's FCS positions. That is, further econometric analyses are needed to directly test the hypothesis that changes in Chinese and/or Indian FCS positions were associated with changes in Latin American FCS levels, as has been attempted by Eichengreen and Tong (2005) and Cravino, Lederman, and Olarreaga (forthcoming), among others. In any case, the data and the findings of this paper suggest that the threat from China and India in terms of FDI might be the dog that did not bark. 


\section{References}

Blonigen, Bruce, Ronald B. Davies, and Keith Head. 2003. "Estimating the knowledgeCapital Model of the Multinational enterprise: Comment." American Economic Review 93: 980-994.

Carr, David L., James R. Markusen, and Keith E. Maskus. 2001. "Estimating the Knowledge-Capital Model of the Multinational Enterprise." American Economic Review 91: 693-708.

Chantasasawat, B, K.C. Fung, H. Lizaka, and A. Siu. 2005. "FDI flows to Latin America, East and Southeast Asia and China: Substitutes or Complements?" Working Paper 595, Department of Economics, University of California, Santa Cruz.

Cravino, Javier, Daniel Lederman, and Marcelo Olarreaga, [2006], Forthcoming.

Eichengreen, Barry, and Hui Tong. 2005. "Is China FDI Coming at the Expense of Other Countries?” NBER Working Paper 11335, Cambridge, Massachusetts.

Garcia-Herrero, Alicia, and Daniel Santabárbara. 2005. "Does China Have an Impact on Foreign Direct Investment to Latin America?" Working Paper 0517, Bank of Spain, Madrid.

IADB [Inter-American Development Bank]. 2004. The Emergence of China: Opportunities and Challenges for Latin America and the Caribbean.

Rose, Andrew K. 2004. "Does the WTO Make Trade More Stable?" NBER Working Paper 10207, Cambridge, Massachusetts.

UNCTAD [United Nations Conference on Trade and Development]. 2004. World Investment Directory. Geneva and New York: United Nations.

UNCTAD. 2005. World Investment Report. Geneva and New York: United Nations. 


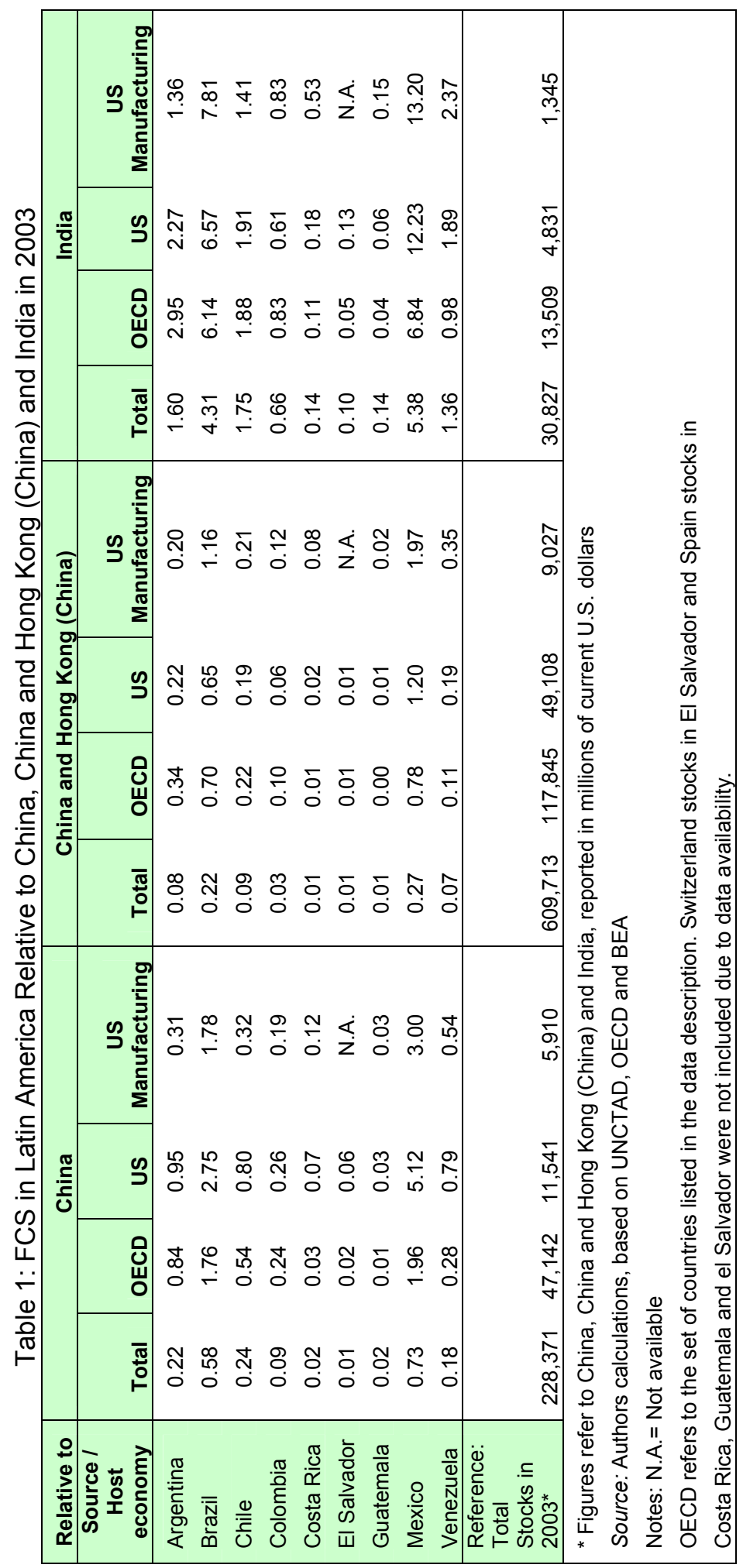




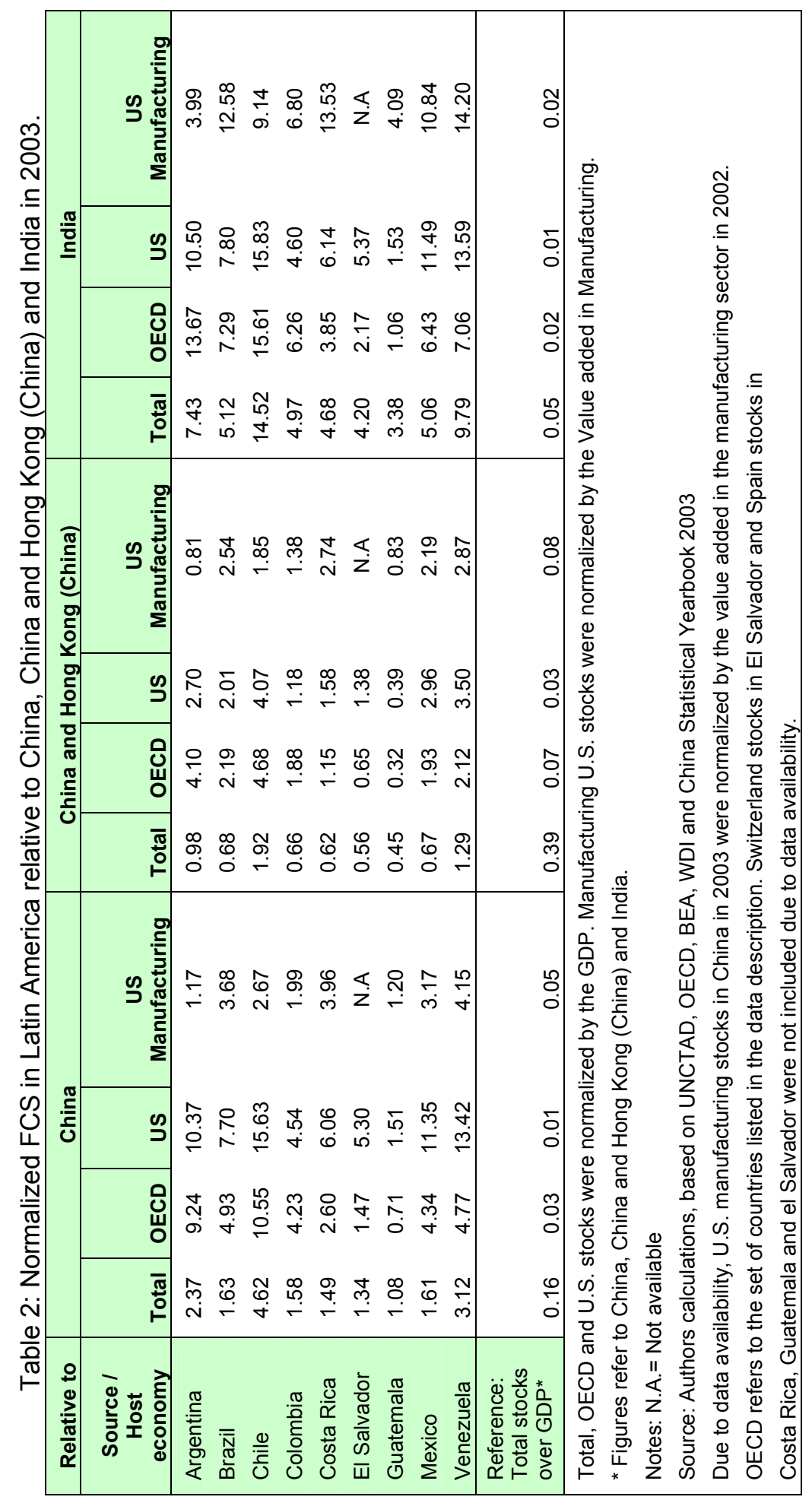




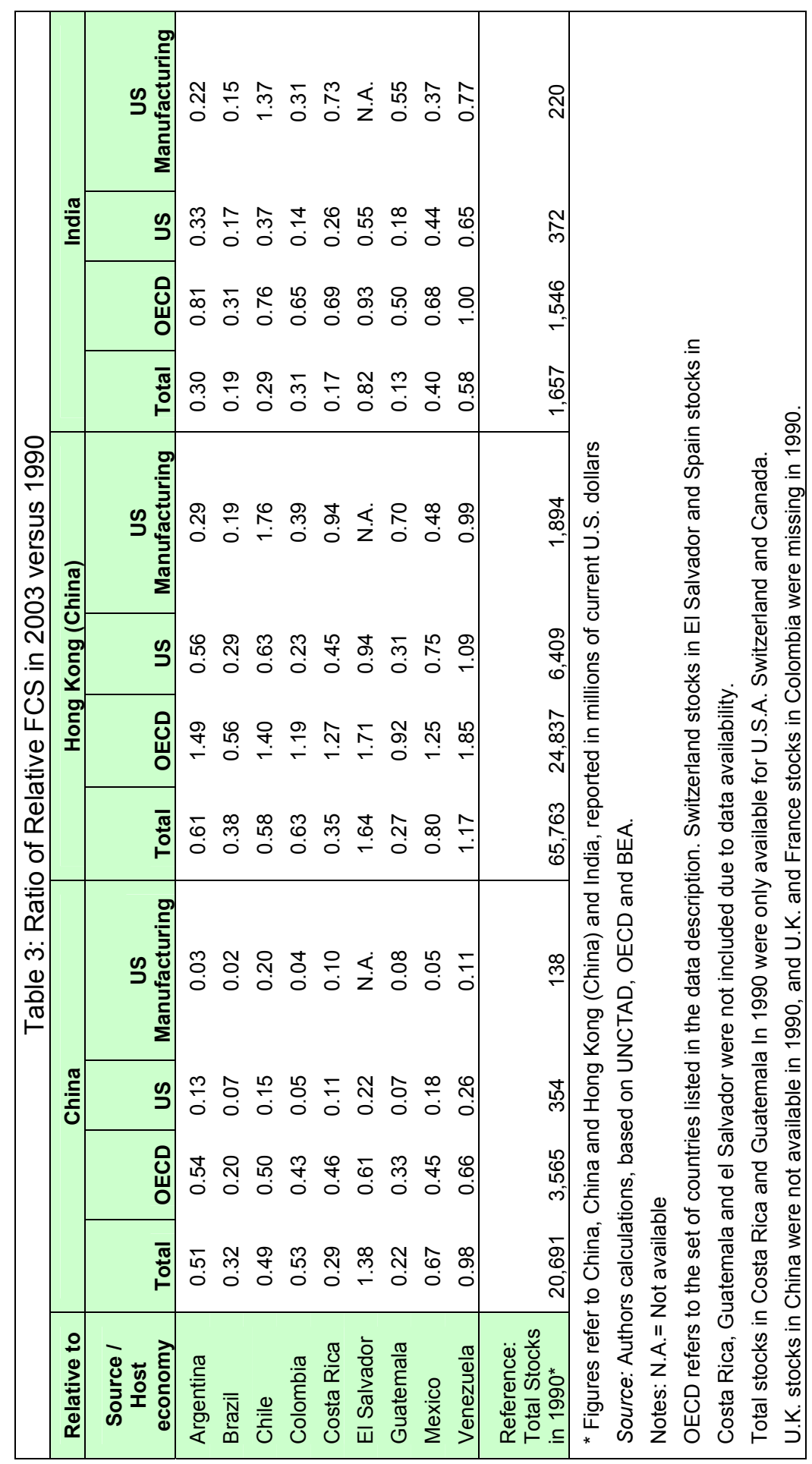




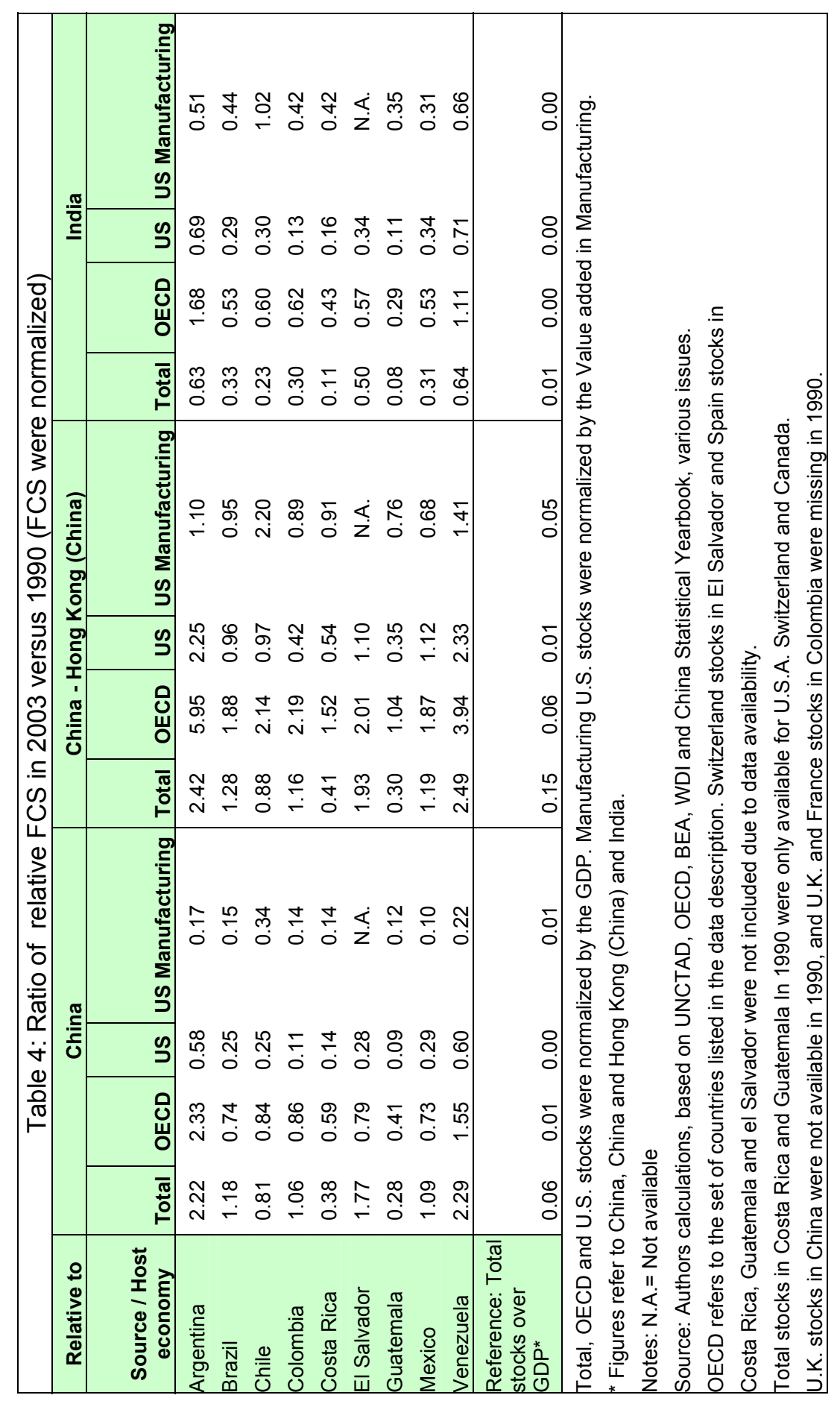




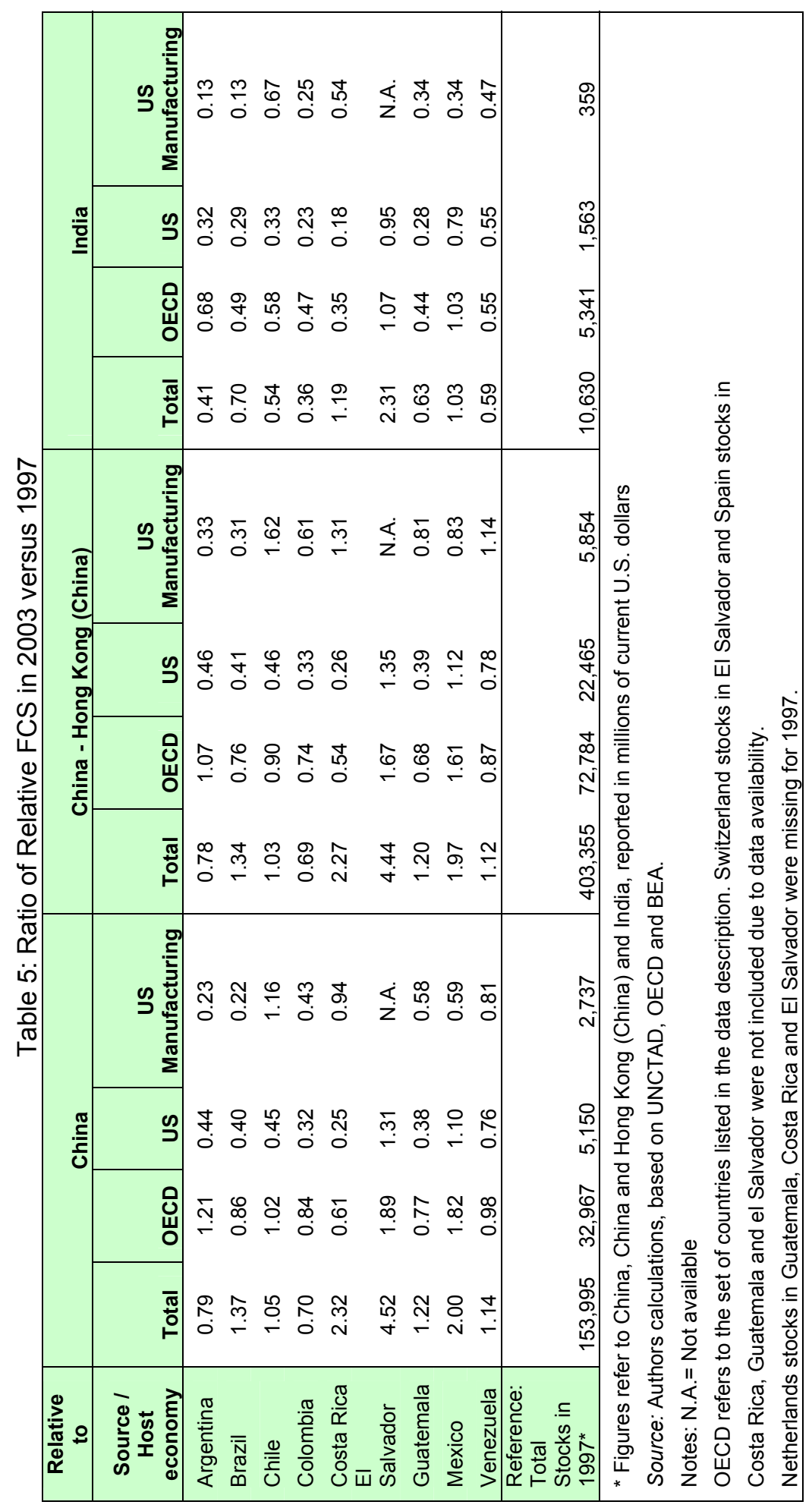




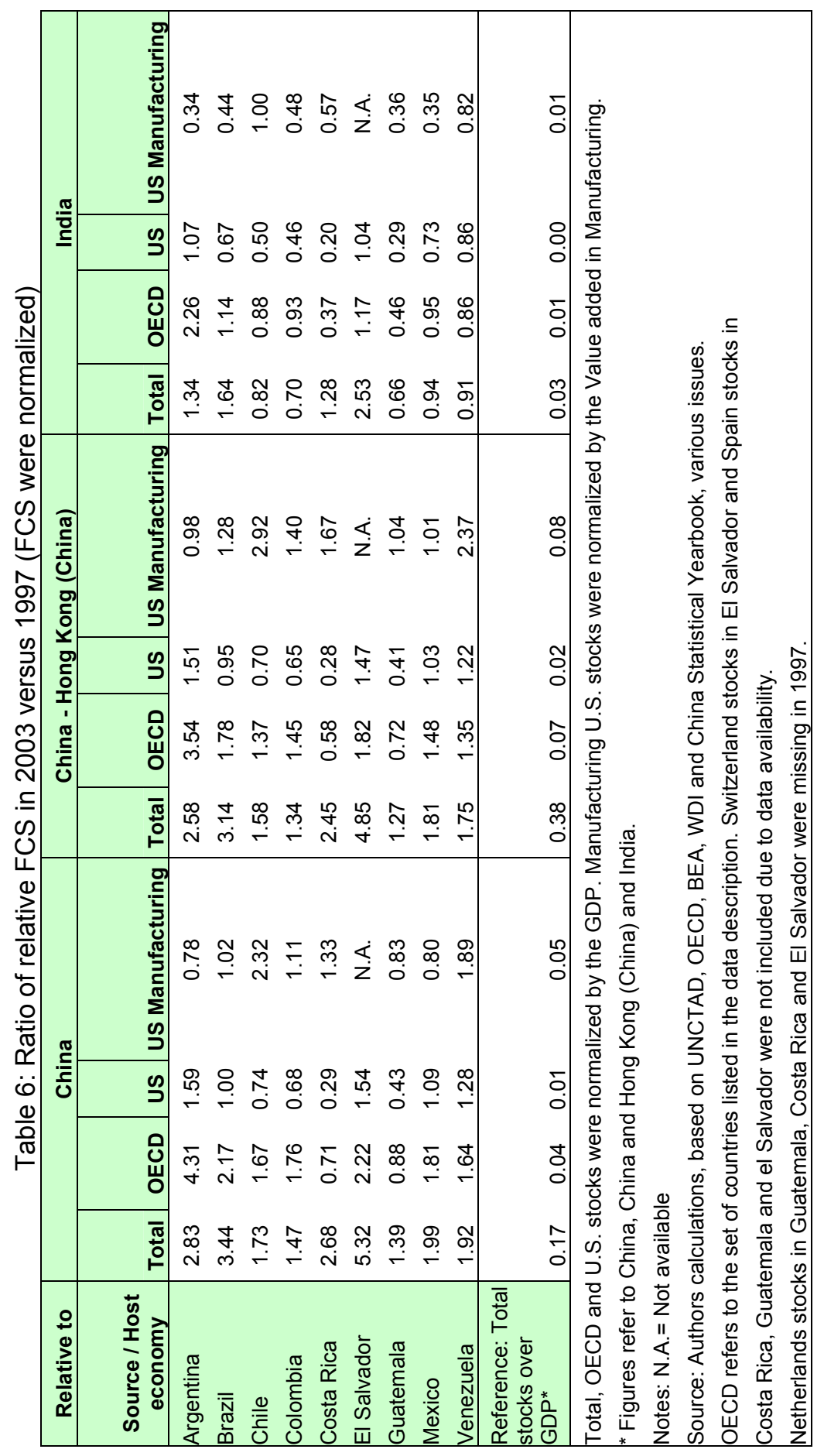




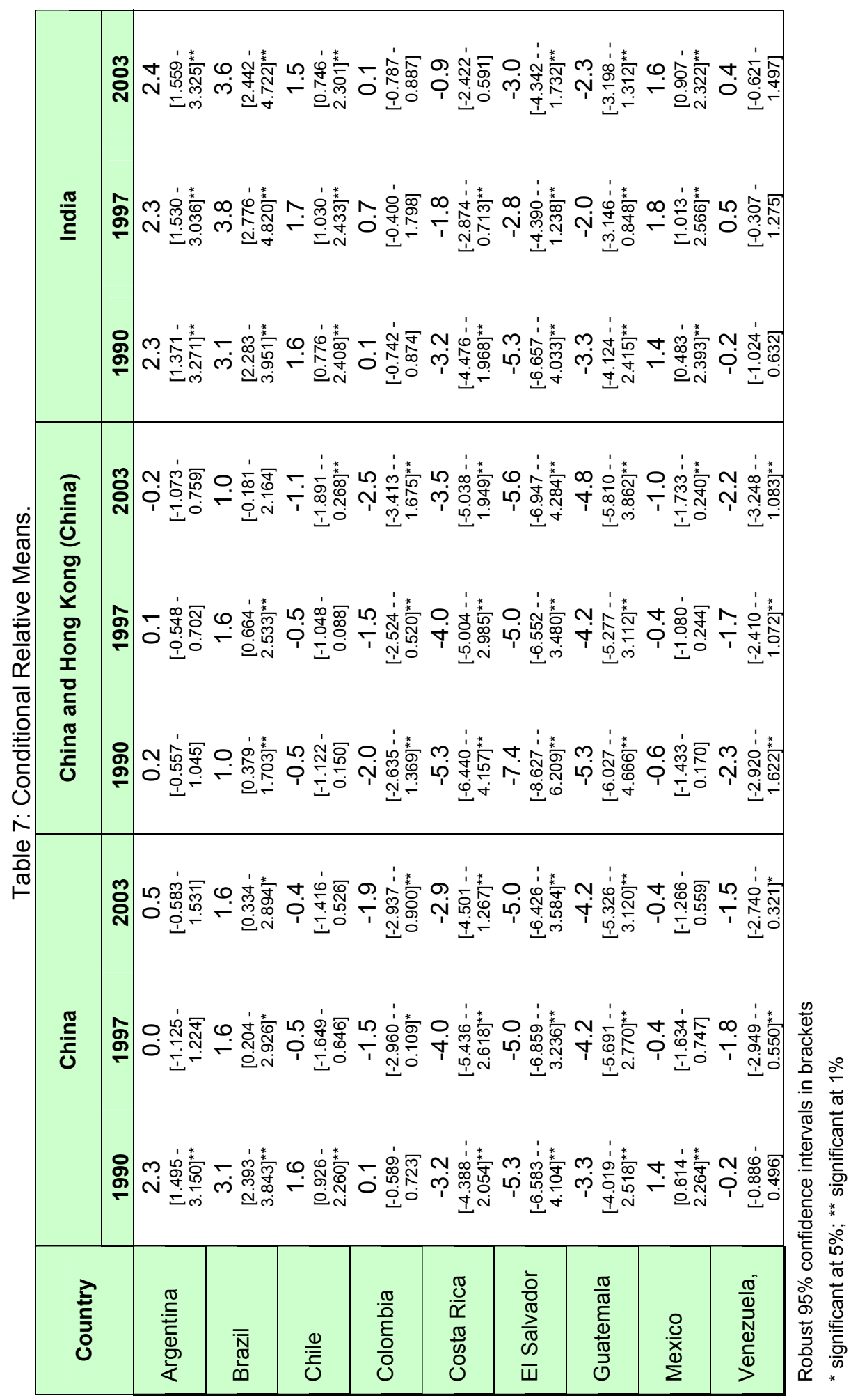

